will give me the useful support of the prestige and publicity of THE LANCET? Every life lost from a preventable disease is a wasted life. "If preventable, why not prevented?" said King Fdward on a memorable occasion. One of the best fields in which to commence operations is among the 160,000 employés of the British Post-office. The measures adopted in France afford a useful example of what can be done.

I am, Sirs, yours faithfully,

Barnes, S.W., June 2lst, 1901. Chartes H. Garland.

\section{OPTIC ATROPHY AND TABES DORSALIS.}

\section{To the Editors of THE LANCET.}

SIRS,-There has to the best of my knowledge never been any theory which satisfactorily accounts for the fact that double optic atrophy coming on early in locomotor ataxia so frequently causes arrest of the disease, and in some cases even permanent improvement. I, therefore, venture to propound the following which I think will account for it in great part, if indeed it does not do so entirely.

The tabetic patient in consequence of failure of eyesight is forced to rely for all his movements more and more on his muscular sense, ordinary sensation, sense of localisation and coördination. He is, in fact, actively engaged in trying to restore the impairments and re-educate these senses every minute of the day when not asleep. The effects of coördinate gymnastics and regulated exercise in tabetics is well known in diminishing the ataxia, \&c. Would not this compulsory training due to the failure of eyesight have the same result, though in a more powerful manner, as it is continually being called into demand? And here, of course, the training is progressive, just as in the gymnastics and regulated and gradual exercises. I cannot recall to my mind any case of locomotor ataxia coming on in persons previously blind from other causes. My experience, of course, is very limited, but I think that statistics would show that the percentage of such is very small. If this is so, it adds a strong argument in favour of my theory. I trust that some meurologists of experience will be able to throw light on the subject and show whether the percentage just mentioned is small or not.-I am, Sirs, yours faithfully,

sune 9th, 1901. EDGAR F. CrRIAX, M.B., Ch.B. Edin.

\section{${ }^{6}$ LEGISLATION AGAINST NATIONAL INTEMPERANCE."}

\section{To the Editors of THH LANCET.}

Sins,-I have to thank my friend Dr. G. Archdall Reid for gis letter published in THE LANCET of Jane 22nd, p. 1790. At last he makes his position clear. He founds his views on Galton not on Weismann, but the distinction is really one without a difference. Both contend for the non-transmissibility of "acquired" modifications or features. The only point of variation is that Galton arrives at his conclusion by one route, Weismann by another. Both views are pure speculations. Dr. Reid therefore bases his views, which are also speculations, on a like foundation. So far, therefore, when he contends that we who believe that acquired characters may be transmitted have no proof of our belief, he possesses no advantage over us. If one view (as a theory) is permissible, the other (as a theory) is equally so. But Dr. Reid thinks that the germ-plasmassuming for the moment that the great divergence between germ and soma contended for by Galton and Weismann is a reality-can never be impressed by acquired characters. I ask him, therefore, in turn, how he knows this? The whole matter is one of explaining certain facts, and I may remind him that there are cases and facts which appear to be as explicable certainly on the theory of the transmission of acquired features as on that of natural selection. If any biologist will demonstrate that the germ-plasm is utterly independent of the body-plasm, then Galton's hypothesis may have a fair chance of passing into the region of demonstrated fact. As it is, I regard Darwin's " pangenetic" theory as a far more likely explanation of the reason of the germ being capable of reproducing parental features. Dr. Reid has over and over again made the assertion that naturalists have ransacked the animal and plant worlds without finding an instance of the transmission of acquired characters. $\mathrm{He}$ would have been more just and correct had he said that be really means that his theory is the only one that explains instances of transmission. In your own columns, Sirs, you have published cases (e.g., those of Dr. W. Duncan) which demand explanation. In Nature of a fortnight ago there is the case of the oysters given by Mr. J. M. Tabor. There is the case of the motmot's feathers alluded to by Darwin. There is the instance of Japanese fowls and their tailfeathers, also alluded to in Nature a week or two ago by Mr. J. M. Cunningham. I might multiply examples, but if Dr. Reid is in earnest in seeking material he will find no lack of such. The opinion that acquired features may be handed on is, to put the case very mildly, just as feasible an explanation of facts as the opposite view. Possibly Dr. Reid does not think the opinions of Mr. Herbert Spencer, Hertwig, Eimer, or Cunningham worth consideration; yet in biology these are names which carry weight and they are those of men opposed, on purely scientific considerations, to the idea that acquired features are never transmissible and that this view can explain no fact of inheritance. The long and the short of it is that Dr. Reid and his opponents are dealing with speculations pure and simple, and the one view is just as tenable as the other. Certain it is also that the one theory is not inconsistent with the other. Both may be correct and both have to be judged by the only safe criterion of any hypothesis-namely, that a good theory explains all the facts and is contrary to none. It has not yet, at least, been demonstrated that the theory that acquired characters may be handed on by processes of heredity is inconsistent with facts.

Edinburgh, June 22nd, 1901. I am, Sirs, yours faithfully,

ANDRET WILSON.

\section{"THE SURGERY OF PREGNANCY AND} LABOUR COMPLICATED WITH TUMOURS."

To the Editors of THE LANCET.

SrRs,-I have read with much interest the letters of Dr. G. E. Herman and Mr. Bland-Sutton and Dr. W. S. Playtair in THE LANCET of Feb. 16th and 23rd. Apart from any possible chance of being misunderstood may I add my contribution of opinion to those already expressed? The times are changed, but have the members of the profession who teach and practise gynæcology changed with them? If anyone interested will refer to Dr. Spencer's paper in the British Medical Journal, No. 1720, p. 1315, he will find an excellent then up-to-date account of the advantages attending the practice of obstetric physicians who performed major abdominal surgery. It is curious that a sort of general statement which appeared in the Gynacological Journal, vol. ix., 1894, pp. 451-454, has left very little for anyone to add. Still, as in 1893, "Bartholomew's blocks the way." It is true that, fortunately, neither the reputation of the great hospital nor the sick poor suffer, as in the hands of the very competent staff the work done in abdominal surgery and gynæcology ranks with any other London hospital. In the excellent hospitals of Australasia and New Zealand are many gynæcologists, some of whom are physicians and some surgeons, who are worthy to be ranked with some of their brethren who are now in London, Liverpool, Manchester, and other large cities. So ere we decide one way or the other it is well to have all the facts clearly before us. May I add that I claim to practise what I teach-viz, the very great importance of always endeavouring to make a clear diagnosis before deciding to operate? True, the best men may make mistakes, but he who is "never wrong" has yet to be found.

During the past 20 or 25 years no branch of medical practice has made such great advances as gynæcology. This being granted, is it not natural that there may also exist certain differences of opinion between gentlemen who may have been influenced by their individual experiences and opportunities? For example, some operators are, as a matter of individual experience, advocates of the vaginal rather than the abdominal route for entering the peritoneal cavity. Some prefer to attack diseased renal organs from an incision directly over the kidney, others prefer generally to operate by opening the peritoneal cavity as in abdominal section. Some have, perhaps, abused oöphorectomy and not unfrequently removed one if not both healthy ovaries. At best the patient has to depend on the skill and experience of the gynæcologist whom she may be under, and on his part the operator must treat every case of pregnancy complicated by 